\title{
Declaração de Bolonha no contexto de mercantilização da educação superior: 0 discurso neoliberal dos organismos multilaterais
}

\author{
Telmo Marcon ${ }^{*}$
}

\section{Resumo}

O presente artigo, de natureza bibliográfica e documental, discute a crescente mercantilização da educação. A questão orientadora é pensar se a Declaração de Bolonha propõe políticas educacionais inovadoras ou se aproxima de outros discursos difundidos por organismos multilaterais, de modo especial, o Banco Mundial. No âmbito dessa questão emergem inúmeras indagações em relação à tendência homogeneizadora presente na Declaração, assim como nas políticas educacionais apoiadas pelos organismos multilaterais no contexto de crescente mercantilização da educação superior. Na Declaração, perpassa um paradoxo entre a diversidade e a homogeneização. Há uma confluência de discursos entre os produzidos pelos organismos multilaterais com os presentes na Declaração de Bolonha de 1999, assim como nos comunicados posteriores. Isso expressa uma tendência à flexibilização da educação e das instituições universitárias, não para aprofundar as relações com atores sociais que historicamente ficaram à margem, mas orientada por princípios neoliberais, dentre os quais, a mercantilização da educação superior. Nesse sentido, pode-se dizer que Bolonha não propõe algo inovador, antes busca responder aos desafios de uma educação orientada pela lógica da eficiência e da flexibilidade. Esse processo é paradoxal na medida em que pauta questões importantes como o intercâmbio de estudantes e pesquisadores oriundos de países com experiências plurais em confronto com demandas de um mercado flexibilizado que prima por padrões e princípios homogeneizadores. Buscando aprofundar alguns desses aspectos inicia-se com uma introdução, na sequência reconstrói-se alguns pressupostos do neoliberalismo e o papel dos organismos multilaterais, com destaque para o Banco Mundial e, na parte final são expostas algumas reflexões sobre a Declaração de Bolonha e as considerações finais.

Palavras-chave: Acordos de Bolonha. Políticas Educacionais. Mercantilização da Educação superior. Diversidade. Homogeneidade. 


\section{Considerações iniciais}

A tensão entre homogeneização e diversidade não é novidade, ao contrário, perpassa a história da humanidade, tendendo mais para a homogeneização do que para o reconhecimento da diversidade. As ciências sociais de um modo geral e a sociologia da educação, particularmente, constituíram-se no âmbito da tradição positivista, primando pela regularidade e pelas recorrências. As pesquisas desenvolvidas por Durkheim sobre a natureza da educação resultaram na clássica definição de que ela "é a ação exercida, pelas gerações adultas sobre as gerações que ainda não se encontram preparadas para a vida social [...]" (1967, p. 41). Como ele chegou a essa conclusão? Ele busca em distintas experiências educativas desenvolvidas ao longa da história elementos recorrentes que resultaram na formulação do conceito. Essa conclusão traduz um procedimento constitutivo das ciências sociais que ele sistematiza na obra As regras do método sociológico (DURKHEIM, 1987). Evidente que, no âmbito das experiências históricas, os diversos povos e as nações desenvolveram práticas educativas diversas de acordo com as estratificações e as classes sociais, mas ao mesmo tempo primaram elementos unificadores e produtores de coesão social (DURKHEIM, 1967, p. 41-47). São esses elementos de regularidade que foram tomados como objeto central das ciências, não apenas as sociais. A busca pelas regularidades se justifica por estar orientada pela ordem, ao contrário da diversidade e da pluralidade que exige capacidade para trabalhar com ideias, projetos e interesses distintos.

O que há de novo no contexto atual em relação à tensão entre homogeneização e diversidade, especialmente no âmbito da educação superior e, mais particularmente, no contexto da Declaração de Bolonha de 1999? Pode-se acenar, mesmo que de modo provisório, que há um conjunto de indicativos que expressam essa tendência, entre os quais: a) a existência de várias iniciativas no âmbito interno de muitos países, mas também internacionalmente, do desenvolvimento de sistemas de avaliação em larga escala pautados em regularidades que desembocam em políticas de regulação e ranqueamentos; b) a evidência de uma forte tendência de instrumentalização da educação superior alinhada às demandas do mercado e às transformações das instituições de educação superior a essas necessidades concretizadas tanto na reestruturação de instituições (flexibilização e enxugamento curricular, por exemplo) quanto no desenvolvimento de pesquisas demandadas por grupos corporativos e empresas, realidade que se traduz numa crescente disputa de recursos entre pesquisadores que estejam mais afinados com essas demandas do mercado (disputas e concorrências entre pesquisadores, constituição de currículos individualizados, ranqueamento de citações); c) o fortalecimento de discursos 
oriundos do mercado (administração empresarial) que é transposto para o âmbito das instituições educativas como se ambas seguissem uma única lógica. Trata-se de um discurso gerencialista (SOUZA, 2005) oriundo do mundo empresarial e da administração que idolatra conceitos como eficiência, eficácia, governabilidade, flexibilização, racionalização, qualidade total, clientela (BOLTANSKI e CHIAPELLO, 2009; BERTOLIN, 2009). Nessa mesma linha de reflexão diz Santos, "Temas como eficiência, competição, performance, choice e accountability ganharam centralidade na agenda educacional" (2005, p. 82). Esses discursos perpassam políticas e programas apoiados por organismos internacionais (multilaterais) como é o caso do Banco Mundial e da OCDE. Para além disso, o apoio e o financiamento de projetos educacionais por parte dessas instituições ficam subordinados a outras mudanças estruturais.

Essas tendências confluem para a mercantilização da educação e a transformação das instituições educativas e, por conseguinte, dos sujeitos que nelas atuam diretamente (professores, gestores, alunos). Uma das consequências imediatas é a supressão de disciplinas e áreas que não contribuem de forma direta e imediata para uma preparação profissional do tipo instrumental. O discurso assentado na imediatez a na formação instrumental vem ganhando espaço no contexto do discurso neoliberal e das transformações em curso no âmbito das políticas educacionais evidenciadas na própria Declaração de Bolonha. Evidentemente, não se pode simplificar processos que são complexos, mas há elementos que apontam para uma tendência homogeneizadora dos processos educativos na Europa nessa política. No entanto, Bolonha não chega a produzir um discurso original, antes situa-se num contexto mais amplo de transformações da educação que vem ganhando impulso nas últimas décadas pela influência de organismos multilaterais, originalmente criados com funções políticas e econômicas, entre os quais destaca-se o Banco Mundial que, muitas vezes não tem relações diretas com gestores em diferentes níveis nacional, estaduais, municipais e ou mesmo de instituições educativas, contribuiu na produção de um discurso que é partilhado internacionalmente por muitos gestores. Nesse sentido, a influência de um discurso mercantilista é muito mais ampla e profunda do que se visualiza num primeiro momento.

Tentando dar conta de alguns elementos dessa problemática, o texto desenvolve, a seguir, algumas reflexões sobre os pressupostos neoliberais produzidos de modo mais intenso desde a década de 1980 , a atuação dos organismos multilaterais com destaque às políticas educativas implementadas e apoiadas pelo Banco Mundial; reconstrói, ainda, alguns elementos do documento base da Declaração de Bolonha de 1999, bem como de documentos produzidos posteriormente pelos ministros signatários e, por fim, as considerações finais. 


\section{0 avanço do discurso neoliberal}

A gênese do pensamento neoliberal situa-se no contexto da Segunda Grande Guerra Mundial, tendo como um dos principais expoentes Hayek, de modo particular sua obra Caminhos da servidão, publicada em 1944. A crítica fundamental dos neoliberais tem dois alvos: o Estado do Bem-estar social implementado na Europa e o new Deal nos Estados Unidos. Na primeira situação, o Estado é criticado por se constituir num agente regulador da vida social, política e econômica, em parceria com sindicatos e empresas privadas, estendendo sua atuação na excessiva garantia de serviços públicos e proteção da população. O New Deal ("novo acordo", "novo trato"), por sua vez, incluiu um conjunto de programas no âmbito da economia implementados pelo governo Franklin Roosevelt nos Estados Unidos, entre 1933 e 1937 com o objetivo de fazer frente aos problemas decorrentes da Grande depressão de 1929 (ANDERSON, 2003, p. 9). O foco principal das críticas dos neoliberais incide nessa intervenção do Estado.

Na década de 1970, o discurso neoliberal ganha um forte impulso capitaneado de modo mais vigoroso por dois protagonistas: Margaret Thatcher, primeira ministra da Inglaterra e Ronald Reagan, presidente dos Estados Unidos. Nesse contexto ganha espaço não apenas um novo discurso, mas também um conjunto de práticas políticas que incluem reformas estruturais como as privatizações de empresas estatais ligadas ao aço, eletricidade, petróleo, gás água, sistema financeiro. Além da privatização de bancos ocorre, de modo acentuado desde a década de 1980, um aumento expressivo da especulação financeira com profundas consequências para vários países, especialmente na América Latina. Segundo Anderson, o governo de Thatcher incrementou um conjunto de política que "contraiu a emissão monetária, elevando as taxas de juros, baixaram drasticamente os impostos sobre os rendimentos altos, aboliram controles sobre os fluxos financeiros, criaram níveis de desemprego massivos, aplastaram greves, impuseram uma nova legislação anti-sindical e cortaram gastos sociais" (2003, p. 12). Tudo isso, segundo Anderson, tinha como objetivo "a reanimação do capitalismo avançado mundial" (2003, p. 15). O autor afirma que o neoliberalismo é uma ideologia de alcance mundial, visto possuir "um corpo de doutrina coerente, autoconsciente, militante, lucidamente decidido a transformar todo o mundo à sua imagem, em sua ambição estrutural e sua extensão internacional" (2003, p. 22).

A análise feita por Gentili na obra A falsificação do consenso: simulacro e imposição na reforma educacional do neoliberalismo localiza no Consenso de Washington o marco fundamental de sistematização da ideologia neoliberal. $\mathrm{O}$ diagnóstico de fundo reconhece uma profunda crise no capitalismo que demanda ações 
articuladas de alcance global. Gentili retoma as principais proposições sistematizadas pelo Consenso de Washington, denominação dada pelo pesquisador John Williamson, com base num conjunto de princípios, entre as quais destacam-se: disciplina fiscal; redefinição das prioridades nos gastos públicos; reforma tributária; liberalização do setor financeiro; manutenção das taxas de câmbio competitivas; liberalização comercial; atração das aplicações de capital estrangeiro; privatização das empresas estatais; desregulação da economia e proteção de direitos autorais (GENTILI, 1998, p. 14).

Esse leque de proposições incide praticamente em todas as dimensões da vida social. Em razão disso, ganha uma amplitude maior, mesmo em áreas não explicitas como é a educação. Na medida em que as propostas tocam em questões estruturais profundas, a educação não fica imune. A ideologia neoliberal conseguiu uma expansão muito rápida e com impactos nas políticas nacionais profundas em muitos países. Esse processo ganha um fôlego extra com a crise do socialismo real, expresso na queda do muro de Berlin em 1989.

Que resultados as políticas baseadas nos pressupostos neoliberais trouxeram? Uma primeira observação diz respeito ao cuidado para não generalizar os resultados, visto que eles não são lineares nem do ponto de vista do espaço (regiões e países), nem em relação às diferentes dimensões da realidade. Anderson faz um balanço geral e conclui que de um modo geral não houve uma "revitalização do capitalismo" na intensidade prevista, mas do ponto de vista social, as políticas neoliberais aprofundaram as desigualdades.

Política e ideologicamente, todavia, o neoliberalismo alcançou êxito num grau com o qual seus fundadores provavelmente jamais sonharam, disseminando a simples ideia de que não há alternativas para os seus princípios, que todos, seja confessando ou negando, tem de adaptar-se a suas normas (2003, p. 23).

Essa última conclusão é fundamental para se compreender os caminhos apontados por vários organismos internacionais, independente do grau de desenvolvimento dos países ou regiões e das suas condições e contradições internas. Há orientações gerais que independem das realidades nacionais. O discurso da ausência de alternativas, ou seja, de que há uma única possibilidade ${ }^{1}$ criou um pessimismo que resultou, de um modo geral, em uma aceitação acrítica das proposições formuladas pelos organismos multilaterais que ficaram ainda mais fortalecidas com a crise do socialismo real, especialmente após a queda do muro de Berlin. Dali em diante as proposições neoliberais (tanto na retórica quanto na prática) ganham um novo fôlego e uma certa universalização. O Banco Mundial e o FMI desempenham, nesse contexto, um papel fundamental no convencimento de que a única alternativa para a solução dos problemas é um alinhamento aos seus receituários. 


\section{Organismos multilaterais e a educação: o papel do Banco Mundial}

O recorte proposto para esse artigo é o do Banco Mundial. Poder-se-ia eleger outros organismos multilaterais, criados desde o fim da Segunda Guerra Mundial, com objetivos políticos e econômicos, mas que passaram a atuar de modo sistemático no campo da educação em sentido mais amplo e nas políticas educacionais, de modo particular. ${ }^{2}$ Esses organismos têm funções distintas e atuam em diferentes áreas, por vezes, confluem em suas proposições e, em outros momentos, entram em conflito. Entre eles pode-se destacar: o Fundo Monetário Internacional (FMI), o Banco Mundial (BM), Banco Interamericano de Desenvolvimento (BID), a Organização das Nações Unidas (ONU), Acordos Gerais sobre Tarifas e Comércio (Gatt), posteriormente (1995) transformado na Organização Mundial do Comércio (OMC), a Organização para a Cooperação e o Desenvolvimento Econômico (OCDE), criada em 1961 para substituir a Organização Europeia para a Cooperação Econômica (Oece), que havia sido criada em 1947, no contexto de implementação do Plano Marshall. Em 1944 foi criado ainda o Banco Internacional para Reconstrução e Desenvolvimento (Bird) e o Banco Interamericano de Desenvolvimento (BID), oficialmente criado em 1959. Vê-se que a lista não é pequena. O recorte sobre o Banco Mundial justifica-se pelo fato de ser uma instituição com intervenção internacional em vários áreas e muitos recursos e, mais intensamente desde a década de 1980, no campo das políticas educacionais.

Como indica Fontes (2015, p. 9), no prefácio do livro A demolição de direitos: um exame das políticas do Banco Mundial para a educação e a saúde, "Em todos os artigos desse livro, fica evidente quais pautas e como foram integradas às políticas nacionais os diagnósticos e prognósticos do Banco Mundial, convertidos ulteriormente em políticas governamentais e, bem além disso, em reconfiguração dos próprios Estados”. O BM ganha maior destaque na década de 1980, especialmente após a queda do muro de Berlin em 1989, tanto na construção de diagnósticos quanto na indução de políticas públicas e na reestruturação dos Estados (apoio à privatização de empresas públicas e incremento nas parcerias público-privadas).

Os organismos multilaterais não estão isolados dessas transformações mais profundas resultantes da crise do capitalismo e da implementação de políticas neoliberais, ao contrário, contribuem efetivamente para suas consecuções. Daí a necessidade de aprofundar os princípios norteadores das ações, no caso do BM, visto que ele tem uma inserção forte nas políticas educacionais por meio do financiamento de projetos e apoiando conferências e eventos internacionais no campo da educação. A concepção de fundo em relação à educação é de subordiná-la à raciona- 
lidade econômica que se traduz, segundo Fonseca, nos discursos da "igualdade de oportunidades, participação, descentralização e autonomia” (1998, p. 64).

O BM não é uma mera instituição financeira como a denominação pode dar a entender. Ele é um complexo resultante de um conjunto de outros organismos, também com atuação internacional. Segundo Pereira (2015, p. 21-22), fazem parte do complexo do BM o Banco Internacional de Reconstrução e Desenvolvimento (Bird); a Associação Internacional de Desenvolvimento (AID), a Corporação Financeira Internacional (CFI), a Agência Multilateral de Garantia de Investimentos (AMGI), o Centro Internacional para Arbitragem de Disputas sobre Investimentos (CICDI), o Instituto do Banco Mundial (IBM) e o Painel de Inspeção que foi criado em 1993 com a "missão de investigar denúncias de pessoas ou organizações afetadas ou que podem ser afetadas negativamente por projetos financiados pelo Banco Mundial" (PEREIRA, 2015, p. ). Além dessas instituições, o Banco Mundial atua junto com outras instituições como o Fundo Monetário Internacional (FMI), a Organização para o Comércio e Desenvolvimento Econômico (OCDE), entre outras. Esse breve panorama já dá uma ideia preliminar da amplitude de possibilidades de intervenção que essa instituição tem. Mais elementos sobre a história do Banco Mundial, seus desdobramentos e intervenções podem ser buscados em autores como Fonseca (1998; 1999); Pereira e Pronko (2015); Pereira (2015); Pronko (2015); Vior e Cerruti (2015); Vilas (2015); Mello (2015); Junior e Maués (2014), entre outros.

$\mathrm{Na}$ sequência, serão abordados apenas alguns aspectos da vinculação do BM com a educação e com as políticas educacionais. Para Pereira, várias condições e diversos fatores fazem com que o $\mathrm{BM}$ ocupe uma posição privilegiada no cenário mundial: "ser um ator político, intelectual e financeiro, devido à sua condição absolutamente singular de emprestador, formulador e articulador de políticas, ator da sociedade civil e veiculador de ideias sobre o que fazer em matéria de desenvolvimento capitalista" (2015, p. 20). Ainda, segundo Pereira, com o aumento da sua carteira ampliaram-se as áreas de atuação para além da infraestrutura e energia, entre as quais, "política econômica, educação, saúde, habitação, meio ambiente, administração pública e reconstrução nacional pós-conflito" (2015, p. 19).

Esses campos de atuação dão condições políticas ao BM atuar num determinado setor e, em contrapartida para o financiamento, exigir mudanças estruturais em outras áreas. Como observa Gentili (1998, p. 31) e Fonseca (1999), as exigências para a liberação de financiamentos são rigorosas e vão além das razões específicas de um determinado projeto. Dessa forma, os financiamentos ficam condicionados a outros ajustes, por vezes são exigências de outros organismos, caso contrário não são aprovados. "Mesmo quando esse financiamento é assumido de forma direta pelo Banco Mundial e pelo BID, o FMI exerce um papel central no estabelecimento das precondições necessárias para a aprovação dos recursos a serem investidos" 
(GENTILI, 1998, p. 31). A análise de Pereira vai nessa mesma direção quando diz que em maio de 1979 o "BM anunciou a criação de um novo instrumento: o empréstimo de ajustamento estrutural, de desembolso rápido e orientado para políticas, não para projetos de desenvolvimento" (2015, p. 24). Mesmo havendo diferenças entre essas instituições e, por vezes, conflitos de interesses, elas atuam de forma articulada e, assim, ganham maior poder de pressão para que os governos realizem reformas estruturais. Na década de 1990, essas intervenções foram muito expressivas, principalmente na América Latina. Essa discussão foi aprofundada, entre outros, por Paulo Nogueira Batista (2001) no livro Consenso de Washington: a visão neoliberal dos problemas latino-americanos no qual traz um conjunto de elementos dos diagnósticos feitos sobre a crise na América Latina, as propostas formuladas e as intervenções realizadas.

Um ponto central dos discursos feitos pelos organismos multilaterais é o da relação entre educação e desenvolvimento. Os organismos multilaterais defendem essa aproximação, não visando o desenvolvimento nacional, mas a globalização. Como diz Santos, nos últimos vinte anos, "a globalização neoliberal lançou um ataque devastador à ideia de projeto nacional, concebido por ela como grande obstáculo à expansão do capitalismo global” (2005, p. 47). É nesse contexto que cresce, entre as instituições multilaterais, a ideia de que não é possível haver um desenvolvimento econômico sem uma consistente base educacional. A observação de Pronko evidencia que várias instituições reproduzem esse discurso:

A difusão de uma ideologia que ligava fortemente educação e desenvolvimento não foi tarefa apenas da Unesco. Outros organismos tiveram enorme importância: o Comitê de Assistência ao Desenvolvimento (CAD) da Organização para a Cooperação e o Desenvolvimento Econômico (OCDE), as grandes fundações norte-americanas (Ford, Rockefeller e Carnegie, principalmente), além do próprio BM (2015, p. 92).

Para Fonseca (1998, p. 59), em que pese a retórica de educação para todos, reiterada em documentos internacionais a partir de 1990, especialmente após a Conferência de Jomtien, o Banco Mundial já defendia nos anos de 1970 a prioridade para a educação inicial. A preferência por esse nível primário é retomada pelo Banco, em 1995, "no qual são reiteradas algumas evidências empíricas que já haviam sido tratadas no documento de 1980. Entre elas, o aspecto social desse nível de ensino, no que se refere à formação de hábitos e atitudes para o desempenho profissional e a taxa de retorno econômico atribuída ao nível primário" (1998, p. 60). Esse foi o caminho adotado pelo Ministério da Educação no Brasil durante os oito anos do governo de Fernando Henrique Cardoso (FHC), tendo como ministro da Educação Paulo Renato de Souza. Na apresentação que faz da sua obra A revolução gerenciada (2005), ele fala que a ideia do livro nasceu de seminários dados 
na Universidade de Harward para alunos de pós-graduação. Esses seminários, diz Souza:

[..] foram possíveis porque no ano de 2003 eu havia escrito sete trabalhos para o Banco Interamericano de Desenvolvimento (BID) e para o Banco Mundial. Para o BID, foram seis estudos de caso para serem utilizados nos cursos de treinamentos em gestão de políticas sociais organizadas pelo Instituto Interamericano de Desenvolvimento Social (INDES); para o Banco Mundial foi um trabalho sobre a reforma do ensino médio (2205, p. XI).

O governo de FHC assumiu uma posição de alinhamento às políticas educacionais do Banco Mundial ao priorizar o ensino fundamental. Para Fonseca, "o ideal democrático de universalização do ensino foi reduzido à oferta do nível primário, para o qual o Banco recomenda prioridade na assignação dos seus créditos e na distribuição dos recursos públicos dos países em desenvolvimento" (1998, p. 60). $\mathrm{O}$ enfoque proposto pelo BM foi de incrementar a educação básica em detrimento da educação superior. Segundo Pronko, o financiamento público para a educação superior em vista da eficiência e da eficácia do gasto público. "Essa diretriz de política, encampada pelo BM na década de 1990, levaria à reconfiguração do campo da educação superior, transformado agora em educação terciária, espaço por excelência para a constituição de quase-mercados, mediante uma nova forma de gestão: a parceria público-privada em educação" (2015, p. 96).

Os níveis de ensino posteriores deveriam, segundo orientação do BM, seguir critérios seletivos, de acordo com as estratégias políticas que incluíam, também, a cobrança de taxas escolares, especialmente para o ensino superior, a descentralização administrativa e uma progressiva transferência "dos serviços educacionais" para o setor privado (FONSECA, 1998, p. 60). Há nesse discurso um novo enfoque dado ao papel da educação. Ainda, segundo Fonseca, desde a década de 1960, o Banco Mundial "recomenda a extensão da oferta de ensino elementar a todas as crianças e adultos. A educação deveria ser integrada ao trabalho, com a finalidade de desenvolver as competências necessárias às necessidade do desenvolvimento" (1999, p. 169). Um estudo sobre a avaliação do Banco Mundial em relação às políticas educacionais implementadas pelos governos de FHC e de Luiz Inácio Lula da Silva foi feito por Mota Junior e Maués. Para a $\mathrm{OCDE}^{3}$, segundo Daros Junior (2013, p. 16):

[...] a educação possui um papel central como resposta às demandas da reestruturação do capitalismo emergente, sobretudo, a partir do neoliberalismo nos anos 1980-1990, mas também aos impactos sociais dela recorrentes. Propõe-se, portanto, a enfatizar a necessidade da preparação do indivíduo a uma economia que requer uma formação profissional habilitada para os desafios, inclusive da flexibilidade do emprego (2014, p. 1.137-1.152). 
Subjacente ao discurso do BM há uma concepção de educação como mercadoria. Essa discussão é feita por vários autores, entre os quais Santos, quando resume o papel dos defensores dos princípios neoliberais em relação à universidade que é a "transnacionalização do mercado de serviços universitários" (2005, p. 26). Em razão dessa concepção, a universidade pública é fortemente atingida. Nessa mesma linha de reflexão Gentili faz a seguinte reflexão: "trata-se de transferir a educação da esfera política para a esfera do mercado, negando sua condição de direito social e transformando em possibilidade de consumo individual, variável segundo o mérito e a capacidade dos consumidores. A educação deve ser pensada como um bem submetido às regras diferenciadas da competição" (1998, p. 19). Nesse contexto, ganham destaque as parcerias público-privadas. A Cooperação Financeira Internacional (CFI), uma das organizações do BM, tem como foco principal as parcerias público-privadas e a educação. Entre suas prioridades atuais estão a de "ampliar o acesso à educação de qualidade para grupos de média e baixa renda, aumentando, assim, a mobilidade social"; melhorar os padrões de qualidade e eficiência; facilitar o intercâmbio internacional de melhores práticas; ajudar os alunos/instituições a obter acesso a financiamento; proporcionar oportunidades de trabalho para profissionais qualificados; complementar o setor público, a fim de atingir objetivos nacionais em matéria de educação. Expressões como melhores práticas ou boas práticas, derivadas do campo da gestão empresarial, foram incorporadas pelos organismos internacionais vinculadas "à ideia de tomada de decisões baseadas em evidências, para designar um repertório de técnicas, procedimentos e soluções que favorecem a eficiência e a eficácia do processo, independentemente do contexto no ao qual se aplicam" (PRONKO, 2015, p. 103, nota 13).

No âmbito da educação os organismos multilaterais defendem, entre outras ações, as avaliações de larga escala. Não é por acaso que, no Brasil, as avaliações de larga escala tiveram uma expansão expressiva nos dois governos de FHC quando se intensificam políticas pautadas em pressupostos neoliberais e nas diretrizes do BM. Como já foi observado anteriormente neste texto, o ministro da Educação Paulo Renato de Souza atuou como consultor do próprio Banco Mundial.

Os organismos multilaterais atuam em diferentes áreas, mas tem a economia e a administração (gestão) como referência. Daí que há uma prevalência de conceitos extraídos dessas áreas de conhecimento que são estendidos para outras áreas como a educação, sem as devidas ponderações. Dessa forma, inúmeros conceitos como gerencialismo, educação gerenciada ${ }^{4}$, eficiência, eficácia, racionalização de custos, qualidade total, meritocracia, sociedade do conhecimento, aprendizagem continuada ou educação permanente, por vezes traduzida como educação ao longo da vida ${ }^{5}$, ganham centralidade e novos significados no âmbito da educação e das 
políticas educacionais. Como diz Fonseca, "a ênfase no aspecto financeiro submete as reformas da área educacional aos critérios gerenciais e de eficiência que tocam mais a periferia do que o centro dos problemas, isto é, incidem mais sobre a quantificação dos insumos escolares do que sobre os fatores humanos que garantem a qualidade da educação" (1998, p. 64). As conclusões a que chega Pereira (2015, p. 53) em relação à atuação do $\mathrm{BM}$ na educação vão nessa mesma direção, ou seja, suas intervenções seguem a lógica do mercado:

No último quarto de século, a atuação do BM se tornou mais abrangente e intrusiva, combinando a ênfase no ajuste macroeconômico com a reforma da administração pública e o ajuste de políticas sociais (em particular, saúde, educação e programas de alívio da pobreza no campo e nas cidades) nos Estados clientes.

[...] Na verdade, a entidade tem mostrado uma capacidade notável de se adaptar às mudanças em curso no ambiente político e econômico mundial, e seguir promovendo a liberalização econômica, a dilapidação dos direitos trabalhistas e a mercantilização e privatização da vida social e da relação sociedade-natureza, em nome da competitividade global (2015, p. 53).

A análise feita por Bertolin sobre o conceito de qualidade na avaliação educacional desemboca nessa mesma problemática. Segundo o autor:

Alguns dos principais termos utilizados pelos que apresentam uma visão economicista da educação superior ao se referirem à qualidade são "eficiência" e "empregabilidade". Em tempos de grande competição de mercado e contenção de custos, a palavra "eficiência" tornou-se uma espécie de requisito básico para as diversas áreas de administração pública e privada, bem como para uma parcela significativa da sociedade no que se refere à aplicação dos impostos e recursos públicos (2009, p. 135).

Como conclui Bertolin (2009, p. 136), o termo eficiência, no contexto da qualidade em educação superior, "vem sendo utilizado principalmente num sentido relacionado com as questões econômicas e de gestão, que englobam, racionalidade de gastos, alta produtividade e alto desempenho gerencial-administrativo". Esses conceitos são apropriados de outros campos do conhecimento (econômica e administração) e transpostos para a educação como se apresentassem a mesma dinâmica.

No entanto, como chama a atenção Pronko, o BM não faz uma intervenção externa e coercitiva sobre governos que ficam passivos e submissos. Desde a década de 1970 o capitalismo tem explicitado um conjunto de contradições, mas também de capacidade de se reordenar e os organismos multilaterais tem contribuição para essa revitalização. Há crises que são mais globais e outras que são mais localizadas e é, nesse sentido, que a intervenção ocorre. Há demandas e necessidades enfrentadas por gestores que se alinham a essas instituições que, em contrapartida, exigem reformas pontuais, mas também estruturais com todas as implicações daí decorrentes. Nesse sentido, conclui Pronko, é “equívoco de [sic] pensar a atuação do 
BM como uma intervenção de fora para dentro (portanto, uma sobredeterminação do âmbito internacional sobre o nacional) e como uma imposição unilateral da qual os governantes locais seriam vítimas" (2015, p. 90).

Essa mesma reflexão é feita por Charlot quando alerta para ter cuidado em relação ao poder que os organismos multilaterais que atuam no campo da educação (OCDE, FMI, BM e OMC) tem em relação aos clientes:

[...] uma organização internacional, na verdade, só tem o poder que lhe conferem os Estados que a sustentam. Às vezes, acha-se que é a organização internacional que decide. Ela toma decisões, claro, mas na lógica e, muitas vezes, conforme os interesses dos países que a mantêm, isto é, que a financiam. Atrás das organizações internacionais, é o poder do capital internacional que funciona (2007, p. 133). ${ }^{6}$

Tratando de outras questões, mas dentro desse mesmo contexto Charlot diz que "a maior mudança da escola na época contemporânea já ocorre nas décadas de 60 e 70 e, portanto, é anterior à globalização. Consiste em pensar a escola na lógica econômica e social do desenvolvimento" (2007, p. 129). Essa é, certamente, a questão de fundo mais impactante nas políticas educacionais que produz um conjunto de implicações nas políticas educacionais e nas instituições de ensino. Pensar a educação como mercadoria ou estritamente articulada com desenvolvimento econômico traz um conjunto de implicações não apenas para a educação, mas também para a democracia, como se refere Nussbaum na obra Sin fines de lucro: por qué la democracia necessita de las humanidades, especialmente o capítulo 7 que trata dos desafios de uma educação para a democracia (2010, p. 161-189). São essas questões, entre outras, que precisam ser repostas nos debates atuais.

Essa mesma crítica é formulada por outros teóricos críticos, entre os quais, Boaventura de Sousa Santos. Na obra A universidade no século XXI: para uma reforma democrática e emancipatória da Universidade, ele faz um diagnóstico importante sobre os rumos da educação superior. Identifica que há uma crescente perda de autonomia das instituições educativas devido às relações subservientes que elas estabelecem com o mercado. A própria ideia de ciência, instrumentalizada em vista da produção de tecnologia, contribuiu muito para a transformação das instituições de educação superior e dos centros de pesquisa. Para Santos, a:

[...] perda de prioridade na universidade pública nas políticas públicas de Estado foi, antes de mais nada, o resultado da perda geral de prioridade das políticas sociais (educação, saúde, previdência) induzida pelo modelo de desenvolvimento conhecido por neoliberalismo ou globalização neoliberal que, a partir da década de 1980, se impôs internacionalmente (2005, p. 15).

Sempre é bom destacar que essas transformações não são lineares, portanto, não apresentam os mesmos resultados e nem foram implantadas com a mesma 
profundidade em diferentes continentes, países e regiões. Santos reconhece que os organismos internacionais estão desempenhando um papel decisivo desde a década de 1990. Diz que ao lado do mercado nacional de ensino superior emerge um mercado transnacional que passa a ser transformado, no final dos anos de 1990, "em solução global dos problemas da educação por parte do Banco Mundial e da Organização Mundial do Comércio. Ou seja, está em curso a globalização neoliberal da universidade" (2005, p. 17).

Com base nos breves argumentos fica evidente que há, desde a década de 1990, uma crescente mercantilização da educação. Vários fatores contribuem para acelerar esse processo, entre os quais, a presença ativa dos organismos multilaterais numa dupla dimensão: a produção e a consolidação de um discurso mercadológico e a intervenção por meio de projetos e políticas em vários países e em inúmeros setores, entre os quais, a educação. $O$ discurso que originariamente foi gestado no âmbito das ciências econômicas e da administração passam, progressivamente, para o âmbito da educação. Diante da precariedade de muitas economias, governos são forçados pelas circunstâncias internas e também por opção política interna a buscar recursos financeiros disponibilizados pelos organismos multilaterais que financiam projetos condicionados a reformas estruturais. Como bem observam Boltanski e Chiapello, especialmente na primeira parte que trata da Emergência de uma nova configuração ideológica (2009, p. 81-194), emerge na década de 1990 um discurso que procura colocar no mesmo plano diferentes dimensões da realidade social. Nesse contexto, ocorrem profundas transformações na organização econômica e administrativa, que impactam, particularmente nas áreas sociais. Tudo passa pelo crivo econômico e tratado como provisório, desde o trabalhador até o conhecimento. Souza (2005, p. 6) reproduz esse discurso quando diz: "O conhecimento torna-se obsoleto a cada cinco ou dez anos; da mesma forma, o padrão tecnológico da sociedade se renova em espaços de tempos semelhantes" (2005, p. 6). Charlot critica esse discurso que tende a mercantilizar a sociedade e a educação: "Com efeito, a lógica neoliberal da concorrência tende a reduzir a educação a uma mercadoria escolar a ser rentabilizada no mercado dos empregos e das posições sociais e isso faz com que formas de aprendizagem mecânicas e superficiais, desconectadas do sentido do saber e de uma verdadeira atividade intelectual, tendam a predominar" (2007, p. 135-136).

Evidentemente haveria muitos outros argumentos a serem apresentados para fundamentar a tese de que há uma crescente mercantilização da sociedade com profundos impactos na educação, especialmente na superior. Por ora, os argumentos apresentados são suficientes para fundamentar essa hipótese. Cabe agora tra- 
zer alguns elementos da Declaração de Bolonha para averiguar até que ponto ela não é expressão desses discursos.

\section{Declaração de Bolonha}

A Declaração de Bolonha resultou de um consenso de 29 ministros de educação de países europeus que assinaram, em junho de 1999, um primeiro documento bem resumido, com duas páginas, no qual são apontadas algumas intenções a serem atingidas no prazo dos dez anos seguintes. Existem pesquisas e trabalhos publicados sobre esse evento, seus desdobramentos no âmbito interno dos países, bem como no continente europeu, e também os seus impactos em outros países e continentes, mas não é nosso objetivo fazer esse resgate. Além disso, existem distintas compreensões em relação a esse acordo, desde posturas em sua defesa até discussões de fundamentação crítica que avaliam seus limites. Santos é crítico na análise que faz das intenções presentes na Declaração de Bolonha:

A estratégia da EU é baseada na ideia de que as universidades europeias não estão por agora preparadas para competir em boas condições (ou seja, em condições lucrativas) no mercado transnacional da educação superior. Há, pois, que defendê-las e prepará-las para competir. É este o sentido político das Declarações da Sorbonne e de Bolonha e das reuniões de seguimento que se seguiram. O objetivo é criar um espaço universitário europeu que, pese embora as especificidades de cada país - que são de manter quase sempre possível - deve ter regras comuns quanto às estruturas curriculares, sistemas de certificação e de avaliação [...] (2005, p. 36).

Nesta seção, a pretensão é de analisar essa Declaração no contexto do discurso neoliberal e das políticas disseminadas pelos organismos multilaterais. Pretende-se reforçar a tese apresentada por Dirk Stederoth, no artigo intitulado A ideia de formação (Universitária) e sua deformação econômica: um cântico final, no qual faz uma análise dos impactos de Bolonha, especialmente na Alemanha. Ao analisar as transformações recentes na educação na Alemanha diz que elas "não têm a ver apenas com as reformas estruturais que, há mais de dez anos, vêm unificando, sob o título de Processo de Bolonha, o espaço universitário europeu. Tais problemas expressam muito mais uma economização crescente dos sistemas de formação em todos os níveis" (2003, p. 175-188). Desse ponto de vista, pode-se dizer que a Declaração de Bolonha não cria algo original, mas é resultante do desdobramento de um conjunto de políticas que já vinham sendo implementadas por organismos multilaterais em outros países e continentes.

Entre as várias questões que podem ser formuladas é se a Declaração de Bolonha prima pela pluralidade de experiências educativas construídas nos diferentes países europeus ou se ela avança em direção à homogeneização. A declaração 
retoma um conceito muito referido pelos organismos multilaterais que é o da sociedade do conhecimento, mas utiliza-o com outra denominação: "Europa do Conhecimento". O conhecimento, concebido num sentido geral, é fator de crescimento sustentável, humano e social e também "um elemento indispensável à consolidação e enriquecimento da cidadania Europeia, capaz de oferecer aos seus cidadãos as aptidões necessárias para enfrentar os desafios do novo milênio, a par com a consciência de partilha dos valores e de pertença a um espaço social e cultural comum" (DECLARAÇÃO DE BOLONHA, 1999, p. 1). A conclusão expressa nesse parágrafo permite questionar até que ponto existe de fato na Europa um espaço social e cultural comum? Não está aqui um indicativo de um projeto homogeneizador?

Nessa mesma perspectiva homogeneizadora, pode-se destacar outros elementos como o expresso no primeiro objetivo da Declaração que é o da "adoção de um sistema com graus acadêmicos e de fácil equivalência". Para que isso ocorra é fundamental a elaboração de ementas e bibliografias que tenham afinidade, ou seja, que tenham certa uniformidade. O quinto objetivo parece estar na mesma direção: "Incentivo à cooperação Europeia na garantia da qualidade com o intuito de desenvolver critérios e metodologias comparáveis" (DECLARAÇÃO DE BOLONHA, 1999, p. 2). O que é comparável se não o que identifica e aproxima, ou seja, que é recorrente? Os processos avaliativos, que também constituem uma das preocupações da Declaração, tem em vista valorizar a diversidade de experiências ou tende a padronizá-las? A livre circulação de estudantes tem em vista qual horizonte? É para intercambiar diferentes perspectivas construídas em seus espaços regionais ou nacionais ou o intercâmbio pressupõe elementos comuns aos quais os alunos vão se adaptar? São algumas questões que parecem fazer parte dos paradoxos presentes na Declaração, na parte final que diz:

Com isto, comprometemo-nos a atingir estes objetivos no âmbito das nossas competências institucionais e respeitando inteiramente a diversidade das culturas, línguas, sistemas de ensino nacionais e a autonomia das Universidades - para consolidar o Espaço Europeu do Ensino Superior. Com esse fim, seguiremos os caminhos da cooperação intergovernamental, em conjunto com as organizações europeias não-governamentais que tenham autoridade no campo do ensino superior. Esperamos, de novo por parte das Universidades, uma resposta pronta e positiva e uma contribuição ativa para o sucesso deste nosso empenho (DECLARAÇÃO DE BOLONHA, 1999, p. 2).

O paradoxo está, de um lado, em afirmar a diversidade de experiências educativas e culturais (línguas) e, de outro, a construção de padrões comuns. Como resolver isso? A tendência parece estar mais na produção de parâmetros aos quais as instituições de educação superior tem de se adequar, ou seja, os ministros da educação esperam que essas instituições deem uma resposta positiva e contribuam para a realização dos princípios da Declaração. 
As reflexões de Boaventura de Sousa Santos são importantes nessa direção. Ao afirmar a diversidade como potencializadora de transformações em diferentes âmbitos (multicultura, democracia, produção da subsistência, educação, entre outras), está destacando o papel positivo e as potencialidades que a diversidade tem. Afirmar a diversidade como possibilidade de enriquecimento entre os países europeus não significar negar o que existe de comum, ou seja, não significa questionar a internacionalização. Ao contrário, esta precisa estar ancorada nas múltiplas experiências construídas e, por meio do diálogo, ganhar impulso. O problema é se a internacionalização proposta não está sendo mediada por interesses do mercado que, em boa parte, está globalizado e busca realizar seus interesses. A se confirmar essa hipótese ela colide com os anseios daqueles que acreditam numa formação qualificada, capaz de desenvolver capacidades nos sujeitos para além da instrumentalização profissional. Isso implica numa formação cidadã. A concepção de educação que vem da tradição Humboldt passa a ser substituída por uma nova concepção de educação orientada "por critérios de eficiência segundo objetivos específicos (antes de tudo econômicos) inscritos nos currículos de instrução profissional" (STEDEROTH, 2013, p. 185).

A análise de Biachetti e Magalhães apresenta a mesma perspectiva ao analisar as transformações nas instituições de ensino superior no contexto da Declaração de Bolonha:

A Universidade europeia, sobretudo nas suas matrizes humboldtiana e newmaniana, afirmou a sua identidade institucional por preservar-se das influências do exterior na procura do conhecimento. Presentemente, parece estar encaminhando-se no sentido de fazer do exterior, isto é, do mundo econômico, o esteio da definição da sua própria missão. O sacrifício aos deuses da relevância social e econômica são agora pedras de toque da definição identitária das instituições de ensino superior europeias e do mundo (2015, p. 236).

A abertura para a internacionalização é fundamental para a Universidade se reestruturar institucionalmente, visto que de um modo geral, ela se constituiu para dentro e se protege, mesmo em relação à sociedade. Charlot (1979) já discutia esse problema da Universidade na década de 1970, denunciando-a como ideológica por ser incapaz de dialogar sistematicamente com a sociedade. O problema é que o diálogo que está sendo proposto entre a Universidade e a sociedade está fortemente pressionado por interesses do mercado concebido como regulador da uma própria sociedade em substituição ao papel do Estado. Em contraposição a essa tendência, observa Santos (2005, p. 100-101), há um apelo à democratização da Universidade empreendido por forças progressistas que pressionam a passagem para um modelo pluriuniversitário. Esse modelo, "ao assumir a contextualização do conhecimento e a participação dos cidadãos ou comunidades enquanto utilizadores e mesmo co- 
produtores de conhecimento, leva a que essa contextualização e participação sejam sujeitas a regras que tornem transparentes as relações entre universidade e o seu meio social e legitimem as decisões tomadas em seu âmbito" (2005, p. 100-101). A primeira Declaração de Bolonha, assim como as declarações bianuais posteriores, colocam em pauta essas preocupações? Como pensar na função da pesquisa no âmbito das universidades quando parte expressiva dos seus financiamentos são feitos por grandes corporações, regidas por critérios mercantis?

A avaliação de Stederoth sobre os impactos de Bolonha, especialmente na Alemanha, não são nada positivos. Em sua avaliação, há uma crescente economização dos sistemas de formação em todos os níveis. Entende a economização como a "redução considerável da formação à instrução profissional" e, como isso, a própria formação, "no sentido de instrução profissional, perdeu o status de fim em si mesma, apresentando-se, agora, como caminho operacional para alcançar objetivos prescritos pelo mercado de trabalho. Isso obriga a estrutura das instituições a cumprir tais objetivos" (2013, p. 175-176). O autor destaca, ainda, o problema salarial dos professores que desde 2005 "consiste num salário básico reduzido, que pode ganhar aumentos dependendo da eficiência e da produtividade do trabalho realizado. É verdade que esses acréscimos podem ser alcançados, também, graças ao trabalho destacado no ensino, mas estes são concedidos, antes de tudo, à base da produção particular na pesquisa e da aquisição de recursos externos" (2013, p. 179-180).

Em síntese, Stederoth elenca três importantes consequências concretas decorrentes da Declaração de Bolonha:

a) publicações orientadas pela sua função, mais interessadas na quantidade dos títulos do que na qualidade do conteúdo objetivo (a produção restrita, por exemplo, de Espinosa pouco impressionaria uma banca moderna que decide sobre uma vaga de professor); b) uma prática de nomeação como que de família, pela qual se valoriza cada vez menos a diversidade objetiva em favor dos vínculos temáticos e institucionais; e c) finalmente, o estreitamento dos conteúdos de ensino e de formação em geral, na medida em que a homogeneização da paisagem das pesquisas leva cada vez mais à redução da variedade dos conteúdos do ensino (2013, p. 180).

Além dessas consequências são apontadas outras, como a avaliação feita pelo Pisa que elege algumas áreas em detrimentos de outras, as disputas entre as instituições por pesquisadores que conseguem atrair recursos para seus projetos, o ranqueamento de instituições, um progressivo esvaziamento da ideia de formação. Além disso, como a própria Declaração anuncia, há um objetivo, que é a necessidade de o sistema Europeu ser competitivo e capaz de atrair de alunos de outros continentes, assim como de pesquisadores. "A vitalidade e a eficiência de qualquer civilização podem ser medidas através da atração que a sua cultura tem por outros 
países. Teremos que garantir que o Sistema Europeu do Ensino Superior adquira um tal grau de atração que seja semelhante às nossas extraordinárias tradições culturais e científicas" (DECLARAÇÃO DE BOLONHA, 1999, p. 1).

Para Veiga e Amaral, a avaliação de historiadores que participaram de uma pesquisa sobre a implementação de Bolonha centram-se "na prossecução do objectivo ligado à promoção de um mercado europeu de ensino superior competitivo. Isto demonstra até que ponto o discurso político em torno da atractividade dos sistemas de ensino superior permeia as percepções daqueles que estão envolvidos no processo de implementação" (2011, p. 23). Ao final dessas reflexões, permanece a questão sobre os alcances e interesses envolvidos na reestruturação da educação superior europeia que não tem seu início com a Declaração de Bolonha. No entanto, inúmeros eventos precederam essa declaração, conforme Bianchetti e Magalhaes (2015, p. 225-249), entre outros. Até que ponto os rumos apontados pela Declaração expressam uma tendência mais global de transformações sociais, política e econômicas? Mesmo tendendo a afirmar que na Declaração de Bolonha, assim como comunicados bianuais posteriores (COMUNICADO DE PRAGA, 2001; COMUNICADO DE BERLIM, 2003) ${ }^{7}$, há uma preocupação em assegurar a autonomia e a diversidade de experiências educativas desenvolvidas pelas instituições de educação superior, há elementos presentes nesses mesmos documentos que apontam para uma tendência padronizadora.

\section{Considerações finais}

Em primeiro lugar, é importante destacar que o tema aqui tratado não é extremamente complexo porque tem inúmeros elementos envolvidos e daí a necessidade de recortar alguns elementos. Em segundo, que a reflexão aqui desenvolvida teve como eixo problematizador o papel dos organismos multilaterais na produção de discursos e de práticas que extrapolam em muito o âmbito político e econômico e se estendem, progressivamente, para o campo da educação. A questão norteadora foi de identificar aproximações entre os discursos dos organismos multilaterais em relação à economia e o mercado e suas implicações para o campo das políticas educacionais e como a Declaração de Bolonha se articula, em certos aspectos, com essas concepções. Mesmo sendo um empreendimento complexo é possível perceber, que alguns conceitos aproximam-se, mesmo que tenham sido abordados de forma breve.

A tese enunciada por Stederoth de que está em curso uma crescente mercantilização da educação sustenta-se na medida em que se aprofunda um confronto entre as proposições dos organismos multilaterais que atuam numa perspectiva de mercantilização da sociedade em geral, e da educação, particularmente, com as 
profundas consequências para as instituições educativas, mesmo para as tradicionais universidades europeias. Essa crítica, no entanto, não tem como pretensão justificar que as Universidades tanto europeias quanto as demais fiquem isoladas das transformações em curso. Ao contrário, é no âmbito das pesquisas que elas podem desenvolver que será possível repensá-las em diálogo com as importantes experiências produzidas historicamente e, também, dando conta dos profundos desafios emergentes. Santos reconhece que "a definição do que é universidade é crucial para que a universidade possa ser protegida da concorrência predatória e para que a sociedade não seja vítima de práticas de consumo fraudulentos" (2005, p. 66). Essa é uma questão que a Declaração de Bolonha não aprofunda, apenas insiste que as instituições educativas respondam positivamente e contribuam para o sucesso das ideias contidas na Declaração.

Há indícios de mercantilização da educação presente na Declaração de Bolonha, mas que não é um fenômeno apenas europeu. Na América Latina, esse fenômeno também se faz presente, mesmo que com ritmos e intensidades distintas. Como ficam as distintas realidades culturais, linguísticas, econômicas, sociais e educativas num projeto que tende a estabelecer padrões, portanto, homogeneizar? No caso europeu, a definição de uma moeda comum e do fortalecimento de um mercado europeu não significa que as diferentes identidades socioculturais tenham desaparecido. Ao contrário, com os crescentes processos imigratórios, a tendência é que as diferenças e tensões se ampliem.

Finalmente uma questão que desafia a todos os sistemas educacionais: as potencialidades de avanço educacional residem na homogeneização ou na qualificação da diversidade? As tendências subjacentes à Declaração de Bolonha parecem apontar para a homogeneização. Isso pode criar facilidades para algumas dimensões, mas, certamente, deixará de avançar em outras perspectivas, levando-se em consideração as múltiplas experiências construídas no passado tanto positivas quanto negativas. É preciso, no entanto, não idolatrar o passado visto que estão em curso um conjunto de mudanças que determinadas respostas já não são mais adequadas. No entanto, subsumi-las também não parece uma saída construtiva. 


\section{The bologna declaration in the commercialization of higher education context: the neoliberal speech of the multilateral organismsresumo em língua estrangeira}

Abstract

This article, in its documental and bibliographic nature, discusses the growing commercialization of education. The guideline is until which point the Bologna Declaration purposes innovative educational policies or approaches to other widespread speeches by multilateral organisms, specially the World Bank. Regarding this question, there are many questionings about the homogenization trend in the Declaration, as in the educational policies supported by the multilateral organisms in the growing context commercialization of the higher education. There is in the Declaration a paradox between diversity and homogeneity. There is also a confluence of speeches among those issued by the multilateral organisms with those present in 1999's Bologna Declaration, as well as in the subsequent releases. This reflects a flexibility tendency of the education and universities, not to improve the relations with the social actors that are historically marginalized, but oriented by neoliberal principles, as the commercialization of the university education. Therefore, is possible affirm that Bologna does not purposes anything innovative, as it looks to respond the challenges of an education oriented by efficiency and flexibility. It is a paradoxical process as it brings to the discussion questions as the student and researches exchange from countries with plural experiences in conflict to a flexible market that is based on homogeneous patterns and principles. In order to analyze these aspects, the article stars with an introduction followed by a reconstruction of a few premises of the neoliberalism and the multilateral organisms' role, specially the World Bank, and some reflections about the Bologna Declaration and the final considerations.

Keywords: Bologna Declaration. Educational Policies. Commercialization of Higher Education. Diversity. Homogeneity.

\section{Notas}

1 A respeito dessa tendência pode-se fazer referência à obra de Fukuyama (1992) sobre o fim da história que exerceu na década de 1990 uma grande influência. Em seus argumento insistia que o fim do comunismo representou o fim de qualquer alternativa, a não ser o capitalismo.

2 Importantes eventos internacionais no âmbito das políticas educacionais tiveram o apoio desses organismos, entre os quais, pode-se destacar: a Conferência Mundial Educação para Todos de Jomtien (1990) que menciona o papel de várias instituições: "Os principais patrocinadores da iniciativa de Educação para Todos (Pnud, Unesco, Unicef, Banco Mundial), cada um no âmbito de seu mandato e responsabilidades especiais, e de acordo com a decisão de suas instâncias diretoras, devem ratificar seu compromisso de apoio às áreas prioritárias de ação internacional [...], e a adoção de medidas adequadas para a consecução dos objetivos da Educação para Todos" (Unesco, 1990). A Conferência de Salamanca de 1994 contou com a participação de 92 representantes de governos e apoio de 25 organizações internacionais.

3 Segundo Charlot, importantes reformas e conceitos educacionais foram elaborados pela OCDE, entre os quais reforma da matemática moderna; o conceito de qualidade da educação, a ideia de economia do saber, assim como a ideia de formação ao longo de toda a vida. "A OCDE é o centro do pensamento neoliberal no que tange à educação. Não é de admirar-se disso quando se sabe que foi explicitamente criada para promover a economia de mercado" (2007, p. 133). 
4 Não é por acaso que o título do livro do ex-ministro da Educação do governo FHC, Paulo Renato de Souza, é Revolução gerenciada: a educação no Brasil (1995-2002).

5 Segundo Pronko (2015, p. 95) duas iniciativas da OCDE lançadas nos 1970 tornaram-se estruturantes na orientações de política educacional nas décadas seguintes: a ideia da educação ao longo da vida e a ênfase na comparação entre países por meio de indicadores educacionais, favorecendo políticas de avaliação da qualidade de reconhecimento internacional, como a prova do Pisa.

6 A OCDE recebe, segundo Charlot, "25\% do seu orçamento dos Estados Unidos. No FMI, em 2005, os Estados Unidos tinham 17\% dos votos, a França 5\%, Arábia Saudita 3,2\%, Índia 1,9\%, Brasil 1,4\%, Indonésia 1\%. Juntos, Índia, Brasil e Indonésia, com quase 500 milhões de habitantes, têm menos peso no FMI do que a França, com 60 milhões. No Banco Mundial, o número de votos de cada país depende do capital que ele colocou no Banco. A organização mais democrática, apesar de ser muito criticada, é a OMC, onde cada país tem um voto. A OMC não tem poder de decisão. A sua função é organizar as discussões entre os vários países e são estes que celebram contratos. Contudo, a OMC tem um poder importante: depois de um convênio ter sido assinado, a OMC arbitra os conflitos e ela já decidiu a favor de países do sul, contra os Estados Unidos ou a União Europeia” (2007, p. 133).

7 A partir de Conferência de Bolonha os signatários da Declaração de 1999 continuaram reunindo-se a cada dois anos para avaliar e acompanhar os desdobramentos da Declaração inicial. Assim ocorreu em 2005 o Comunicado da reunião de Bergen; em 2007 o Comunicado da reunião de Londres; em 2009 o Comunicado da reunião de Louvain; em 2010 o Comunicado da reunião de Budapeste e Viena (2010) e em 2012 o Comunicado da reunião de Bucareste.

\section{Referências}

ANDERSON, Perry. Balanço do neoliberalismo. In: GENTILI, P.; SADER, Emir (Org.). Pós-neoliberalismo: as políticas sociais e o Estado democrático. 6. ed. Rio de Janeiro, Paz e Terra, 2003, p. 9-23.

BATISTA, Paulo Nogueira. O consenso de Washington: a visão neoliberal dos problemas latino-americanos. 3. ed. São Paulo: Consulta Popular, 2001.

BERTOLIN, J. C. G. Qualidade em educação superior: da diversidade de concepções a inexorável subjetividade conceitual. Avaliação, Campinas, v. 14, n. 1, p. 127-149, mar. 2009.

BIANCHETTI, Lucídio; MAGALHÃES, António M. Declaração de Bolonha e internacionalização da educação superior: protagonismo dos reitores e autonomia universitária em questão. Avaliação, Campinas, v. 20, n. 1, p. 225-249, mar. 2015.

BOLTANSKI, Luc; CHIAPELLO, Ève. O novo espírito do capitalismo. São Paulo: Martins Fontes, 2009.

CHARLOT, B. Educação e globalização: uma tentativa de colocar ordem no mercado. Sísifo Revista de ciências da educação, Lisboa, n. 4, out./dez. 2007, p. 129-136.

CHARLOT, Bernard. A mistificação pedagógica: realidades sociais e processos ideológicos na teoria da educação. Rio de Janeiro: Zahar, 1979.

COMUNICADO DE PRAGA. A caminho da área europeia de ensino superior. Comunicado do encontro dos Ministros Europeus do Ensino Superior Praga, 19 de maio de 2001. Disponível em: <http://www.ond.vlaanderen.be/hogeronderwijs/bologna/links/language/2001_Prague_Communique_Portuguese.pdf $>$. Acesso em: set. 2015.

COMUNICADO BERLIM. Conferência de Ministros Responsáveis pelo Ensino Superior. set. 2003. Disponível em: <http://www.ond.vlaanderen.be/hogeronderwijs/bologna/links/language/2003_Berlin_communique_Portuguese.pdf>.Acesso em: set. 2015. 
DAROS JUNIOR, Armando. A presença da OCDE no Brasil no contexto da avaliação educacional. Jornal de Políticas Educacionais, Curitiba, n. 13, p. 13-20, jan./jun. 2013.

DECLARAÇÃO DE BOLONHA. Disponível em: <http://www.ehea.info/Uploads/Documents/1999_Bologna_Declaration_Portuguese.pdf>. Acesso em: maio 2015.

DURKHEIM, Emile. Educação e sociologia. São Paulo: Melhoramentos, 1967.

DURKHEIM, Émile. As regras do método sociológico. 13. ed. São Paulo: Nacional, 1987.

FONSECA, Marília. O Banco Mundial como referência para a justiça social no terceiro mundo: evidências do caso brasileiro. Revista da Faculdade de Educação, São Paulo, v. 24, n. 1, p. 37-69, jan./jun. 1998.

FONSECA, M. O Banco Mundial e a educação: reflexões sobre o caso brasileiro. In: GENTILI, Pablo (Org.). Pedagogia da exclusão: crítica ao neoliberalismo em educação. 5. ed. Petrópolis, 1999. p. 169-195.

FONTES, Virgínia. Prefácio: desigualdades, assimetrias e adesão subalterna - interrogações urgentes sobre Estados e o papel do Banco Mundial. In: PEREIRA, João Márcio Mendes et al. (Org.). A demolição de direitos: um exame das políticas do Banco Mundial para a educação e a saúde (1980-2013). Rio de Janeiro: Escola Politécnica de Saúde Joaquim Venâncio; Fiocruz, 2015, p. 9-12.

GENTILI, Pablo. A falsificação do consenso: simulacro e imposição na reforma educacional do neoliberalismo. Petrópolis: Vozes, 1998.

MELLO, Hivy Damásio Araújo. O Banco Mundial e a reforma educacional no Brasil: a convergência de agendas e o papel dos intelectuais. In: PEREIRA, João Márcio Mendes et al. (Org.). A demolição de direitos: um exame das políticas do Banco Mundial para a educação e a saúde (1980-2013). Rio de Janeiro: Escola Politécnica de Saúde Joaquim Venâncio; Fiocruz, 2015, p. 153-179.

MOTA JUNIOR, William Pessoa da; MAUÉS, Olgaíses Cabral. O Banco Mundial e as políticas educacionais brasileiras. Educação \& Realidade, Porto Alegre, v. 39, n. 4, p. 1.137-1.152, out./ dez. 2014.

NUSSBAUM, Martha. Sin fines de lucro: por qué la democracia necessita de las humanidades. Buenos Aires: Katz, 2010.

PEREIRA, João Márcio Mendes. Poder, política e dinheiro: a trajetória do Banco Mundial entre 1980 e 2013. In: PEREIRA, João Márcio Mendes et al. (Org.). A demolição de direitos: um exame das políticas do Banco Mundial para a educação e a saúde (1980-2013). Rio de Janeiro: Escola Politécnica de Saúde Joaquim Venâncio; Fiocruz, 2015, p. 19-63.

PEREIRA, João Márcio Mendes; PRONKO, Marcela. Introdução. In: PEREIRA, João Márcio Mendes et al. (Org.). A demolição de direitos: um exame das políticas do Banco Mundial para a educação e a saúde (1980-2013). Rio de Janeiro: Escola Politécnica de Saúde Joaquim Venâncio; Fiocruz, 2015, p. 13-15.

PRONKO, Marcela. O Banco Mundial no campo internacional da educação. In: PEREIRA, João Márcio Mendes et al. (Org.). A demolição de direitos: um exame das políticas do Banco Mundial para a educação e a saúde (1980-2013). Rio de Janeiro: Escola Politécnica de Saúde Joaquim Venâncio; Fiocruz, 2015, p. 89-112. 
SANTOS, Boaventura de Sousa. A universidade no século XXI: para uma reforma democrática e emancipatória da universidade. 2. ed. São Paulo: Cortez, 2005.

SOUZA, Paulo Renato de. A revolução gerenciada: educação no Brasil (1995-2002). São Paulo: Prentice Hall, 2005.

STEDEROTH, Dirk. A ideia da formação (universitária) e sua deformação econômica: um cântico final. Revista Espaço Pedagógico, Passo Fundo, v. 20, n. 1, p. 175-188, jan./jun. 2013

UNESCO. Declaração Mundial sobre Educação para todos e Plano de Ação para Satisfazer as Necessidades Básicas de Aprendizagem. Jomtien, Tailândia: mar.1990.

VEIGA, Amélia; AMARAL, Alberto. Uma interpretação do olhar da história sobre Bolonha. História. Revista da FLUP, Porto, série IV, v. 1, p. 29-40, 2011.

VILAS, Carlos M. O Banco Mundial e a reforma do Estado na América Latina: fundamentos teóricos e prescrições políticas. In: PEREIRA, João Márcio Mendes et al. (Org.). A demolição de direitos: um exame das políticas do Banco Mundial para a educação e a saúde (1980-2013). Rio de Janeiro: Escola Politécnica de Saúde Joaquim Venâncio; Fiocruz, 2015, p. 65-85.

VIOR, Susana; CERRUTI, María Betania Oreja. O Banco Mundial e a sua influência na definição de políticas educacionais na América Latina (1980-2012). In: PEREIRA, João Márcio Mendes et al. (Org.). A demolição de direitos: um exame das políticas do Banco Mundial para a educação e a saúde (1980-2013). Rio de Janeiro: Escola Politécnica de Saúde Joaquim Venâncio; Fiocruz, 2015, p. 113-151. 